\section{References}

1. Schalk E, Färber J, Fischer T, Heidel F. Central venous catheter-related bloodstream infections in obese hematologic patients. Infect Control Hosp Epidemiol 2015;36:995-996.

2. Hentrich M, Schalk E, Schmidt-Hieber M, et al. Central venous catheterrelated infections in hematology and oncology: 2012 updated guidelines on diagnosis, management and prevention by the Infectious Diseases Working Party of the German Society of Hematology and Medical Oncology. Ann Oncol 2014;25:936-947.

3. Schalk E, Hanus L, Färber J, Fischer T, Heidel FH. Prediction of central venous catheter-related bloodstream infections (CRBSIs) in patients with hematologic malignancies using a modified Infection Probability Score (mIPS). Ann Hematol 2015;94:1451-1456.

4. Lenz M, Richter T, Mühlhauser I. The morbidity and mortality associated with overweight and obesity in adulthood: a systematic review. Dtsch Arztebl Int 2009;106:641-648.

5. Anonymous. Clinical guidelines on the identification, evaluation, and treatment of overweight and obesity in adults - the evidence report. National Institutes of Health. Obes Res 1998;6 suppl 2:51S-209S.
6. Schalk E, Toelle D, Schulz S, et al. Identifying haematological cancer patients with high risk for central venous catheter (CVC)-related bloodstream infections at the time point of CVC insertion. 29th European Congress of Clinical Microbiology and Infectious Diseases, April 13-16, 2019, Amsterdam, The Netherlands, abstract P2556. https://www.escmid.org/escmid_publications/ escmid_elibrary. Published 2019. Accessed October 9, 2021.

7. Tölle D, Hentrich M, Pelzer BW, et al. Impact of neutropenia on central venous catheter-related bloodstream infections in patients with hematological malignancies at the time of central venous catheter insertion: a matchedpair analysis. Infect Control Hosp Epidemiol 2019;40:1204-1206.

8. Dossett LA, Dageforde LA, Swenson BR, et al. Obesity and site-specific nosocomial infection risk in the intensive care unit. Surg Infect (Larchmt) 2009;10:137-142.

9. Buetti N, Souweine B, Mermel L, et al. Obesity and risk of catheter-related infections in the ICU. A post hoc analysis of four large randomized controlled trials. Intensive Care Med 2021;47:435-443.

10. Trick WE, Miranda J, Evans AT, Charles-Damte M, Reilly BM, Clarke P. Prospective cohort study of central venous catheters among internal medicine ward patients. Am J Infect Control 2006;34:636-641.

\title{
Trends in antimicrobial susceptibility patterns in healthcare-associated methicillin-resistant Staphylococcus aureus from bloodstream infections: A joinpoint regression analysis
}

\author{
Diana Mayumi Nii MS, Maria Aparecida Vitagliano Martins MD and Carlos Magno Castelo Branco Fortaleza MD, PhD (1) \\ Department of Infectious Diseases, Botucatu School of Medicine, São Paulo State University (UNESP), Botucatu, São Paulo State, Brazil
}

To the Editor-Staphylococcus aureus ranks third among pathogens causing healthcare-associated bloodstream infections in Brazil, and $>60 \%$ of reported isolates are methicillin resistant (ie, MRSA). ${ }^{1}$ The rise of healthcare-associated MRSA in Brazil occurred in the 1990s, mostly due to the extensive spread of the Brazilian epidemic clone (BEC). ${ }^{2}$ BEC harbored the staphylococcal chromosome cassette (SCC) mec type III and were typically resistant to several antimicrobials, such as trimethoprim/ sulfametoxazole (TMP/SMX), quinolones, and clindamycin. For a long time (before the national registration of linezolid and daptomycin), glycopeptides remained as the sole therapeutic option for healthcare-associated MRSA (HA-MRSA) in Brazil. ${ }^{3}$

Recent studies report that BEC has been substituted for clones harboring SCCmec type II, with remarkable increasing susceptibility to TMP/SMX and modest increases in susceptibility to ciprofloxacin and clindamycin. ${ }^{4,5}$ Sporadic findings have indicated that TMX/SMX-susceptible, SCCmec type IV-harboring MRSA clones, which probably originated in the community, have spread within Brazilian hospitals. ${ }^{6,7}$ Susceptibility to TMP/ SMX, ciprofloxacin, and clindamycin has been proposed as a proxy marker of the so-called community-associated MRSA (CA-MRSA) invading hospitals. ${ }^{8}$

Author for correspondence: Carlos Magno Castelo Branco Fortaleza, E-mail: carlos. fortaleza@unesp.br

Cite this article: Nii DM, Martins MAV, and Fortaleza CMCB. (2022). Trends in antimicrobial susceptibility patterns in healthcare-associated methicillin-resistant Staphylococcus aureus from bloodstream infections: A joinpoint regression analysis. Infection Control \& Hospital Epidemiology, 43: 1955-1957, https://doi.org/10.1017/ ice. 2021.448
Time series analysis, especially joinpoint regression techniques, which detect changes in time trends, have been rather infrequently applied to analyze long-term trends in antimicrobial resistance within healthcare settings. With that in mind, we conducted a time series analysis of HA-MRSA bloodstream infections (BSIs) in a teaching hospital from inner Brazil. The Botucatu Medical School teaching hospital has 500 beds and is a tertiary-care referral facility for an area with 500,000 inhabitants. Briefly, we analyzed monthly proportions of resistance to TMP/SMX, clindamycin, and ciprofloxacin among CA-MRSA BSIs from 2005 through 2019. During that 15 years, 2,291 nonduplicate episodes of CA-MRSA BSI were detected. We used Joinpoint version 4.9 software (National Cancer Institute, Calverton, MD) to identify changes in the time trends of those resistance patterns. We used a linear approach, and a minimum interval of 6 months between joinpoints was selected.

Our results are summarized in Figure 1. The overall resistance rates were as follows: TMP/SMX, 26.6\%; clindamycin, 77.6\%; and ciprofloxacin, $73.5 \%$. We found 3 joinpoints for TMP/SMX resistance; the most relevant was followed by an abrupt decrease from $80.2 \%$ to $41.0 \%$ beginning in August 2007. The trend changed to a slower decrease until June 2016 (to $37.5 \%$ ), with a small increase thereafter. Both clindamycin (1 joinpoint in July 2014) and ciprofloxacin (2 joinpoints in February and September 2011, respectively) presented initial decreases followed by slow increase in resistance. Notably, joinpoints in trends were not simultaneous for different antimicrobials.

This picture is more compatible with the substitution of SCCmec type III-harboring BEC for SCCmec II-harboring clones, which has been reported to maintain high levels of resistance to 


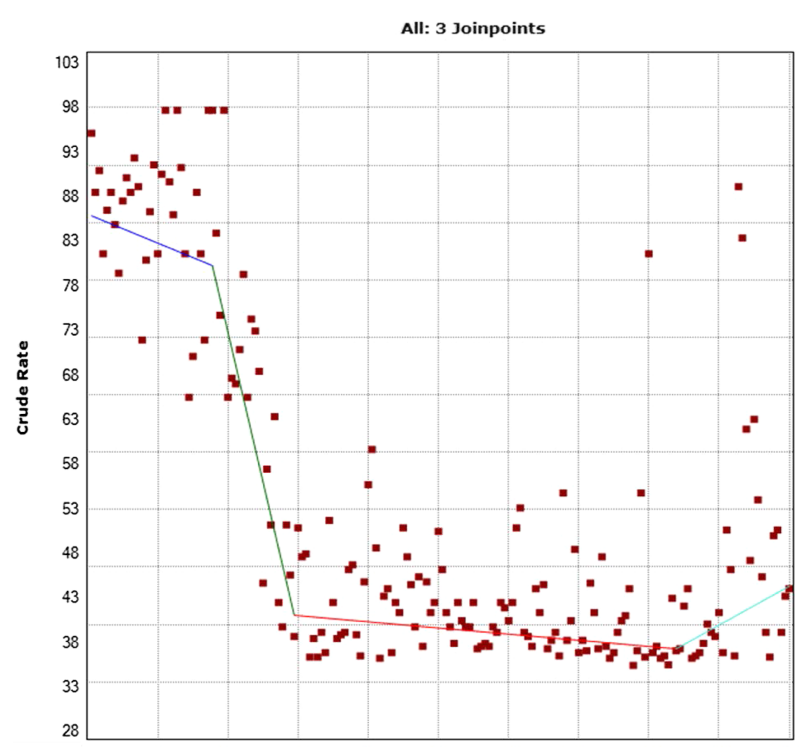

TMP/SMX
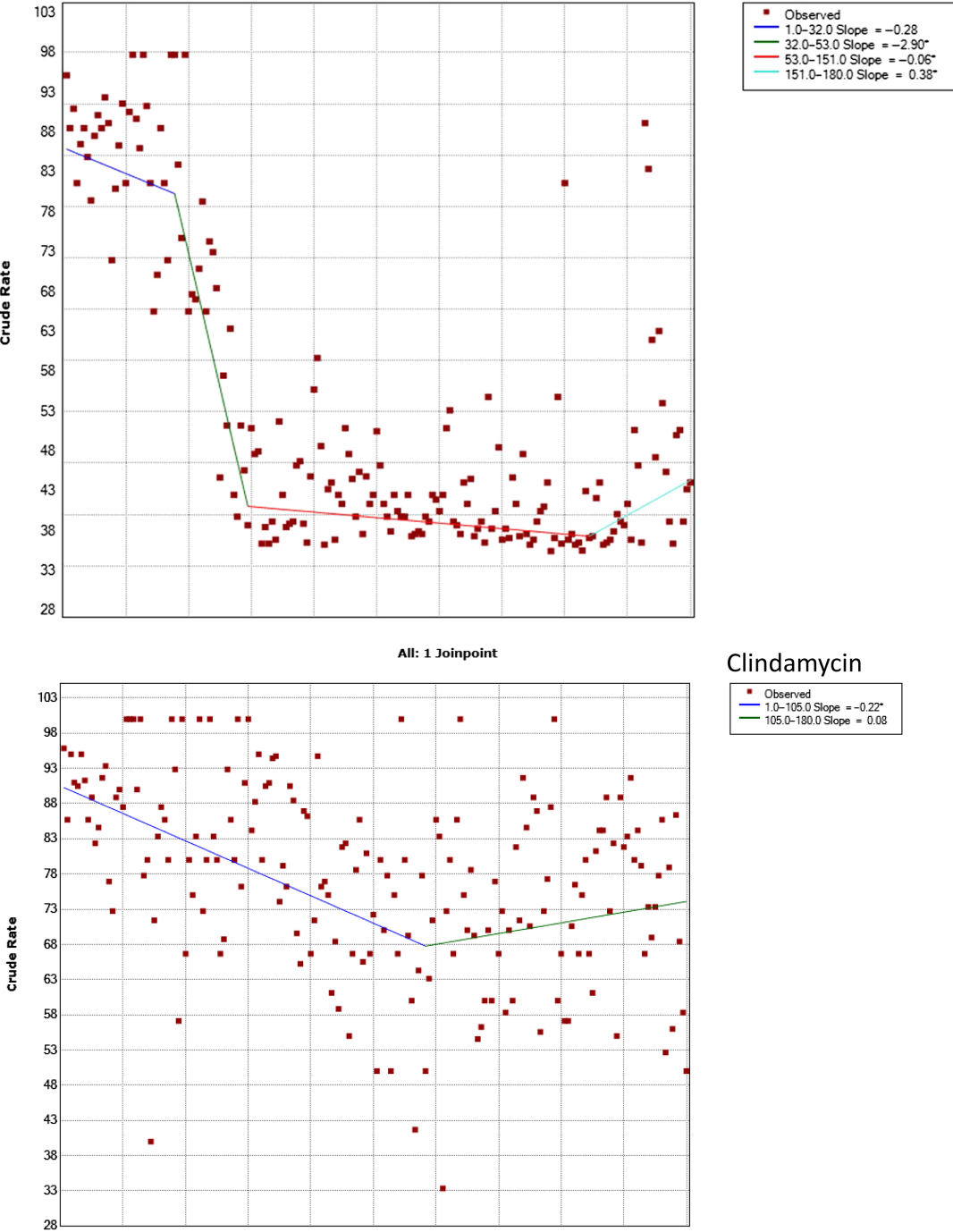

All: 2 Joinpoints

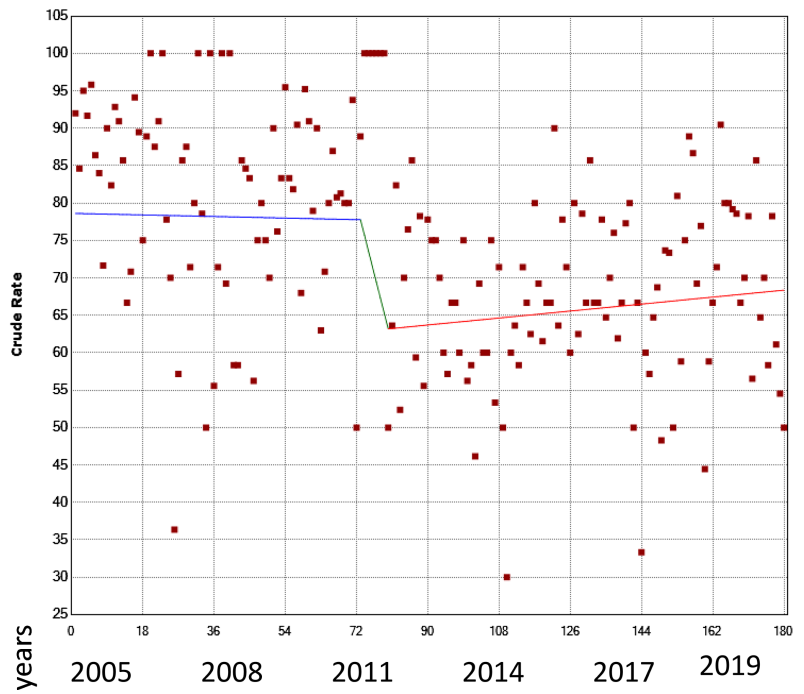

Ciprofloxacin

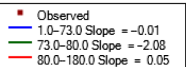

Fig. 1. Joinpoint regression graphics for resistance of healthcareassociated bloodstream infections caused by methicillin-resistant Staphylococcus aureus. Trends (monthly \% changes) are indicated in the box in the right side of the graphics. Note. TMP/SMX, trimethoprim/sulfametoxazole. 
clindamycin and ciprofloxacin ${ }^{4}$ than of invasion by communityassociated, multidrug-susceptible SCCmec IV-harboring MRSA. ${ }^{6}$ Even though our inference is limited by lack of strain and SCCmec typing, the findings are consistent with our recent identification of SCCmec type II in MRSA-colonizing nares and oropharynges of acute-care and long-term admissions of psychiatric patients. ${ }^{9}$ We also analyzed a time series of 15 years using a robust statistical model to detect sudden changes in trends.

In a classic article, Deurenberg and Stobberingh ${ }^{10}$ describe the blurring of distinctions between CA- and HA-MRSA and argue for a pure molecular definition, based on SCCmec typing. Because strain typing is not widely available, especially in low-to-middle income countries, careful long-term follow-up of resistant profiles may provide a reasonable proxy for detecting ecological changes in MRSA infections. Those trends also have therapeutic relevance. Although TMP/SMX is not a reasonable choice for treating MRSA BSI, other less-severe infections (eg, skin infections or phlebitis) acquired during hospital admissions may benefit from that antimicrobial. Further studies combining long-term analysis of time series with molecular typing may provide insights on the past, present, and future of healthcare-associated infectious caused by MRSA.

Acknowledgments.

Financial support. No financial support was provided relevant to this article.

Conflicts of interest. All authors report no conflicts of interest relevant to this article.

\section{References}

1. Agência Nacional de Vigilância Sanitária. Boletim Segurança do Paciente e Qualidade em Serviços de Saúde no. 22. Brasília: ANVISA, 2019.
2. Soares MJDS, Teixeira LA, Nunes MDR, Carvalho MCDS, FerreiraCarvalho BT, Figueiredo AMS. Analysis of different molecular methods for typing methficillin-resistant Staphylococcus aureus isolates belonging to the Brazilian epidemic clone. J Med Microbiol 2001;50:732-742.

3. Rossi F. The challenges of antimicrobial resistance in Brazil. Clin Infect Dis 2011;52:1138-1143.

4. Caiaffa-Filho HH, Trindade PA, Gabriela da Cunha P, et al. Methicillinresistant Staphylococcus aureus carrying SCCmec type II was more frequent than the Brazilian endemic clone as a cause of nosocomial bacteremia. Diagn Microbiol Infect Dis 2013;76:518-520.

5. Duarte FC, Tavares ER, Danelli T, et al. Disseminated clonal complex 5 (CC5) methicillin-resistant Staphylococcus aureus SCCmec type II in a tertiary hospital of Southern Brazil. Rev Inst Med Trop Sao Paulo 2018; 60:e32.

6. Rodrigues MV, Fortaleza CM, Riboli DF, Rocha RS, Rocha C, da Cunha Mde L. Molecular epidemiology of methicillin-resistant Staphylococcus aureus in a burn unit from Brazil. Burns 2013;39:1242-1249.

7. Rossato AM, Primon-Barros M, Rocha LDL, et al. Resistance profile to antimicrobials agents in methicillin-resistant Staphylococcus aureus isolated from hospitals in South Brazil between 2014 and 2019. Rev Soc Bras Med Trop 2020;53:e20200431.

8. Maree CL, Daum RS, Boyle-Vavra S, Matayoshi K, Miller LG. Communityassociated methicillin-resistant Staphylococcus aureus isolates causing healthcare-associated infections. Emerg Infect Dis 2007;13:236-242.

9. Silvestre MADO, Barbosa M, Teixeira NB, et al. Illicit drug users, alcoholics, and psychiatric patients: Staphylococcus aureus and methicillin-resistant $S$. aureus colonization on the border between community and healthcare settings. Infect Control Hosp Epidemiol 2020. doi: 10.1017/ice.2020.1330.

10. Deurenberg RH, Stobberingh EE. The molecular evolution of hospital- and community-associated methicillin-resistant Staphylococcus aureus. Curr Mol Med 2009;9:100-115.

\title{
Retrospective analysis of multidrug-resistant clinical and environmental isolates for the presence of the colistin-resistance gene $m c r-1$
}

\author{
Kara J. Levinson PhD, MPH ${ }^{1}$ (1), Mackenzie E. Collins BS ${ }^{1}$, Anne M. Lachiewicz MD² (1), Andy J. Koltun MS ${ }^{3}$, \\ Mark D. Sobsey $\mathrm{PhD}^{3}$, Elizabeth Christenson $\mathrm{PhD}^{3}$ (1), Jill R. Stewart $\mathrm{PhD}^{3}$ (1) and Melissa B. Miller $\mathrm{PhD}^{1,4}$ (1) \\ ${ }^{1}$ Clinical Microbiology Laboratory, UNC Health, Chapel Hill, North Carolina, ${ }^{2}$ Department of Infectious Diseases, University of North Carolina School of Medicine, \\ Chapel Hill, North Carolina, ${ }^{3}$ Gillings School of Global Public Health, Department of Environmental Sciences \& Engineering, University of North Carolina, Chapel \\ Hill, North Carolina and ${ }^{4}$ Pathology and Laboratory Medicine, University of North Carolina School of Medicine, Chapel Hill, North Carolina
}

To the Editor-Carbapenem-resistant Enterobacterales (CRE) are a public health threat due to increased mortality, cost, and transmissibility of these infections. Although colistin is rarely considered as a last-resort antibiotic to treat CRE infections, increasing reports of plasmid-mediated colistin-resistant CRE isolates worldwide $^{1}$ are concerning. Resistance to colistin is conferred by $\mathrm{mcr}$

Author for correspondence: Kara J. Levinson, E-mail: Kara.Levinson@tn.gov, or Melissa B. Miller, E-mail: Melissa.Miller@unchealth.unc.edu.

Cite this article: Levinson KJ, et al. (2022). Retrospective analysis of multidrugresistant clinical and environmental isolates for the presence of the colistin-resistance gene mcr-1. Infection Control \& Hospital Epidemiology, 43: 1957-1960, https://doi.org/ $10.1017 /$ ice. 2022.8 genes and was first linked to the $m c r-1$ gene. ${ }^{2}$ Since the initial $m c r-1$ report from 2005, researchers have screened isolate collections for $m c r-1$ and have found plasmid-mediated colistin resistant strains in animal and human populations. ${ }^{2}$ At the time of this study, 4 clinical isolates containing the $m c r-1$ gene were identified in the United States, ${ }^{3}$ which has since increased to 55 isolates in at least 21 states. ${ }^{4}$ The overall prevalence, distribution, and impact of $m c r-1$ remain unclear.

In North Carolina, more than half of hospitals have reported CRE infections, ${ }^{5}$ yet resistance to colistin has not been systematically examined. Given the active agriculture industry within the state, the potential to identify $m c r-1$ among clinical and 